\title{
A COMUNIDADE: DA SOCIOLOGIA CLÁSSICA À SOCIOLOGIA CONTEMPORÂNEA
}

Alan Delazeri Mocellim*

Resumo A comunidade é um dos conceitos de maior importância, desde o nascimento da Sociologia. Sua relevância permanece tal que o debate em torno de sua definição é contínuo, adentrando a teoria social contemporânea. Recorrente nesse debate é a dicotomia entre comunidade e sociedade e entre a forma de vida tradicional e a moderna. Neste artigo, debatem-se algumas das principais teorizações clássicas e contemporâneas sobre a ideia de comunidade, enfocando principalmente as teorias que contrapõem as relações sociais comunitárias e a individualização característica da vida moderna. Entre os "clássicos" da Sociologia, optou-se por debater as teorias de Émile Durkheim e Ferdinand Tönnies, e, entre as teorias contemporâneas, optou-se pelas de Michel Maffesoli e Zygmunt Bauman. O objetivo aqui é demarcar divergências e similitudes entre suas diferentes abordagens.

Palavras-chave comunidade; sociedade; individualização; identidade; tribalismo.

\section{THE COMMUNITY: FROM CLASSIC SOCIOLOGY TO CONTEMPORARY SOCIOLOGY}

Abstract The community is one of the concepts of greater importance since the birth of Sociology. Its importance remains such that the debate about its definition is still reaching into the contemporary social theory. Continuous in this debate is the dichotomy between community and society, and between the traditional and modern ways of life. In this article, we discuss some of the major classical and contemporary theories about the idea of community, focusing mainly on the theories that oppose the social community and individualization characteristic of modern life. Among the "classical" Sociology, we chose to discuss the theories of Emile Durkheim and Ferdinand Tönnies, and among contemporary theories, we selected the theories of

Mestre em Sociologia Política pela UFSC e doutorando em Sociologia pela USP. 
Michel Maffesoli and Zygmunt Bauman. The goal here is to mark differences and similarities between their different approaches.

Keywords community; society; individualization; identity; tribalism.

Comunidade é um desses conceitos das ciências sociais que, por mais que o tempo passe, permanecem controversos. Teorias após teorias, décadas após décadas, mesmo com as grandes mudanças que vivemos neste nascente século $\mathrm{XXI}$ - e após as mudanças drásticas que transformaram o mundo do século XX -, não há ainda uma definição que seja hegemônica no debate sobre tal conceito. No entanto, seja no uso cotidiano, seja entre os teóricos sociais, comunidade é um conceito que evoca algo "positivo".

Comunidade é sempre o lugar onde podemos encontrar os semelhantes e com eles compartilhar valores e visões de mundo. Também significa segurança, e é nela que encontramos proteção contra os perigos externos, bem como apoio para os problemas pelos quais passamos. A sociedade pode ser "má", mas a comunidade nunca sofre essa acusação.

Para vislumbrar o uso "comum" e cotidiano do termo comunidade, pode-se recorrer ao dicionário (HouAISs, 2001), em que se encontra definida como: 1) estado ou qualidade das coisas materiais ou das noções abstratas comuns a diversos indivíduos, comunhão; 2) concordância, concerto, harmonia; 3) conjunto de indivíduos organizados em um todo ou que manifestam, geralmente de maneira consciente, algum traço de união; 4) conjunto de habitantes de um mesmo Estado ou qualquer grupo social cujos elementos vivam em dada área, sob um governo comum e irmanados por um mesmo legado cultural e histórico.

Para além dessa definição ainda pouco precisa, a palavra comunidade sugere uma forma de relacionamento caracterizada por altos graus de intimidade, vínculos emocionais, comprometimento moral e coesão social; e não se trata apenas de um vínculo passageiro. As relações caracterizadas como comunidade têm sua continuidade no tempo. O espaço também é importante na caracterização da comunidade, pois esta é localizada e envolve vínculos de proximidade espacial, tanto quanto de proximidade emocional.

A importância da ideia de comunidade no pensamento social é inquestionável, sendo vista como uma das ideias centrais de toda a teoria sociológica, bem como um desenvolvimento importante do pensamento social do século XIX. A importância da comunidade apenas pode ser comparada à importância que a ideia de contrato teve na filosofia política dos séculos anteriores (NISBET, 1967). 
A redescoberta da comunidade no pensamento social aparece como uma crítica ao modelo de sociedade utilitarista, cuja centralidade era colocada no indivíduo e em sua racionalidade. Vinculava-se a um modelo de sociedade e indivíduos racionais, o qual, de certa forma, apresentava-se como fundamentalmente oposto à tradição. As bases desse modelo eram o sujeito racional exaltado no Iluminismo e a aversão iluminista ao feudalismo.

A comunidade foi redescoberta, ganhando nova importância, quando esse modelo de indivíduo racional foi visto como limitado para a compreensão das ações motivadas por laços morais tradicionais. Contudo, sua redescoberta se deveu também à radicalização do modo de vida moderno e a seus processos de urbanização e individualização, de maneira que o modo de vida tradicional veio a ser demarcado a partir de sua profunda diferença em relação às sociedades modernas:

Comunidade é uma fusão de sentimentos e pensamentos, de tradição e compromisso, de adesão e volição. Pode ser encontrado em, ou expressar simbolicamente, localidade, religião, nação, raça, idade, ocupação, ou cruzada. Seu arquétipo, tanto historicamente e simbolicamente, é a família, e em quase todo tipo de verdadeira comunidade a nomenclatura da família é importante. Fundamentais para a força do vínculo da comunidade é a antítese verdadeira ou imaginada formada no mesmo tecido social, pelas relações não-comunais de concorrência ou conflito, utilidade ou aceitação contratual. Estes, por sua relativa impessoalidade e anonimato, destacam os laços pessoais estreitos da comunidade (NisBET, 1967, p. 48).

A comunidade é mais bem percebida diante de sua antítese não comunitária. A emergência da modernidade e a crise das formas de vida tradicionais tornaram mais flagrantes tanto as características modernas quanto as pré-modernas. A modernidade transformou radicalmente as bases das relações sociais comunitárias. A globalização, com seu deslocamento de tempo e local, acabou com as possibilidades de uma demarcação clara dos limites de uma comunidade, de certa forma, dificultando a localização das relações e sua durabilidade ao longo do tempo.

A expansão da cidade sobre o campo, a transformação do vilarejo em metrópole, tudo isso levou a um deslocamento da centralidade do modo de vida comunitário. Com a ampliação dos contatos, mas com a diminuição de sua importância - e considerando a quantidade de pessoas com que um cidadão de uma cidade tem de lidar sem manter vínculo afetivo, principalmente se comparado com o morador de um vilarejo -, a pessoalidade da comunidade foi perdendo espaço para a impessoalidade da metrópole. 
Com a diversidade que se faz presente no aumento do número das pessoas vivendo em uma região e com a impossibilidade de sua limitação territorial - dado que os meios de comunicação e transporte tornam possível uma integração cada vez maior dos territórios globais -, ocorre a ampliação da individualização. Os indivíduos de uma metrópole dispõem de ampla gama de escolhas e opções; no entanto, carecem de uma vida orientada por códigos morais específicos e bem delimitados, típicos da comunidade.

A centralidade da problemática da comunidade e sua tematização e choque com a modernidade são tamanhas que se pode encontrá-la como tema mesmo em Karl Marx e Auguste Comte. Nos escritos de Marx (2006; 2008) - e especificamente nos escritos sobre a vida comunitária na Índia -, encontra-se um repúdio à comunidade tradicional. A dominação inglesa sobre a Ásia é para ele justificável e necessária, sendo encarada como uma forma de levar o Oriente rumo ao "destino histórico" do progresso. Nessa visão, o localismo e suas instituições são sempre obsoletos - principalmente se comparados com o industrialismo moderno. $\mathrm{O}$ socialismo futuro seria nada mais do que o capitalismo sem a propriedade privada, e não um ressurgimento comunitário (NISBET, 1967, p. 66-70).

No caso de Comte, ao contrário de Marx, aparece a necessidade do retorno comunitário como uma forma de reestruturação da modernidade, desestruturada com a decadência das formas tradicionais de organização. A recriação da comunidade é para Comte uma forma de reinstauração de uma moral compartilhada. Para o autor, a sociedade não é nada mais que uma comunidade ampliada; o individualismo nada mais é que uma ideia metafísica; e a comunidade é a verdadeira "essência" do social. No mais, a sociedade positiva, almejada por esse autor, seria uma espécie de forma de vida feudal, um medievalismo, sem a presença do cristianismo ou mesmo de qualquer religiosidade (NISBET, 1967, p. 56-61).

Neste artigo, serão debatidas algumas das principais teorizações clássicas e contemporâneas relacionadas ao conceito de comunidade. Serão enfocadas, principalmente, as teorias que colocam em contraposição as relações sociais comunitárias e a individualização característica da vida na metrópole, bem como as sociedades industrializadas modernas. Ressaltar-se-á, por um lado, o fato de que, em algumas dessas teorias, a emergência da modernidade significa uma decadência das formas de vida comunitárias e mesmo sua impossibilidade e, por outro, que, em determinadas teorias, a decadência das relações sociais comunitárias não significa um contexto de radical individualização, sendo estas substituídas por outras relações que reconstroem de algum modo o vínculo desfeito. 
Entre os "fundadores" da Sociologia, optou-se por debater as teorias de Émile Durkheim e Ferdinand Tönnies e, entre as teorias contemporâneas, optou-se pelas de Michel Maffesoli e Zygmunt Bauman. Seja entre os clássicos, seja entre os contemporâneos, encontram-se divergências no diagnóstico sobre a situação da comunidade. Para alguns deles, a solidariedade dos vínculos comunitários é recriada efetivamente em um novo contexto; para outros, ela é recriada apenas artificialmente, não significando uma ruptura com o individualismo.

A comunidade é um dos conceitos de maior importância no nascimento da Sociologia, sendo considerado um dos conceitos que lhe conferem unidade, transpassando diversas formulações sociológicas (NISBET, 1967). Sua importância permanece tal que o debate em torno de sua definição, ou redefinição, é contínuo, adentrando a teoria social contemporânea.

É recorrente nesse debate a dicotomia entre comunidade e sociedade, entre as formas de vida tradicional e moderna. O que é decisivo aqui é o choque entre comunidade e individualização, e é esse o ponto que será enfatizado nas páginas a seguir.

\section{COMUNIDADE E SOCIEDADE}

Como dito anteriormente, é bastante comum a conceituação da comunidade em oposição à de sociedade. Enquanto a comunidade é tradicional, a sociedade é moderna; enquanto a comunidade agrega, a sociedade desagrega. A mais clássica formulação das ideias de comunidade e sociedade, nesses termos, foi feita por Ferdinand Tönnies (1855-1936). Na visão de Tönnies (1995a), a comunidade - ou Gemeinschaft - é um grupo social demarcado espacialmente. Grupos considerados comunitários contam com elevado grau de integração afetiva e também com alto grau de coesão - e mesmo de homogeneização - entre seus membros, e isso inclui conhecimentos, objetivos, práticas cotidianas e formas de agir e pensar. As normas ocorrem especificamente por meio dos costumes, hábitos e tradições, e as formas de relacionamento social são predominantemente pessoais, o que significa o compartilhamento de valores e também maior grau de intimidade.

Deve-se notar que, em uma forma de vida comunitária, a restrição relativa ao espaço se refere diretamente ao grau em que é possível a manutenção do compartilhamento de valores - a ponto de as relações continuarem configurando um grupo coeso. Essa limitação não se refere apenas ao espaço, mas ao número de membros, e é bastante razoável sugerir que os limites da comunidade são os limites da família, da aldeia e das pequenas cidades. 
Uma resenha de Durkheim (1995, p. 113) sobre Tönnies mostra a "imagem de comunidade" evocada pelo último:

A Gemeinschaft é a comunidade. Ela constitui uma unidade absoluta que é incompatível com a distinção em partes. Para merecer o nome de comunidade, mesmo se estiver organizado, um grupo não é uma coleção de indivíduos que diferem uns dos outros; é uma massa, indiferenciada e compacta, que só é capaz de se mover em conjunto, e é direcionada pela própria massa, ou por uma de suas partes incumbida da direção. É um agregado de mentes tão fortemente coeso que ninguém é capaz de se mover independentemente dos outros.

Também em Max Weber (1987, p. 77) pode-se encontrar uma conceituação de comunidade que permite vislumbrar algo similar:

Chamamos de comunidade a uma relação social na medida em que a orientação da ação social, na média ou no tipo-ideal, baseia-se em um sentido de solidariedade: o resultado de ligações emocionais ou tradicionais dos participantes.

Aqui encontram-se a solidariedade, a relação afetiva e o compartilhamento de tradições como o determinante da comunidade.

A comunidade, para Tönnies (1995a), desenvolveu-se a partir de três diferentes instâncias: o parentesco, a vizinhança e a amizade. A primeira emerge da vida familiar e fundamenta-se na autoridade dos membros da família - sendo essa autoridade traduzida em termos de idade, força e sabedoria. A segunda emerge da vida em comum, do território partilhado. Nesse caso, as necessidades de trabalho e de uma organização comum promovem o compartilhamento dos hábitos, dos conhecimentos e a emergência das tradições. A terceira emerge da semelhança de interesses e formas de pensar. Ela nasce da similitude de atividades, mas deve ser alimentada por encontros frequentes, sendo mais comum nas aldeias e pequenas cidades. De maneira diferente, pode-se falar de comunidade de sangue, de lugar e de espírito e também notar que, mesmo nomeadas como sendo diferentes comunidades, são encontradas em conjunto e fortemente ligadas.

A comunidade de sangue acha-se regularmente ligada às relações e participações comuns, quer dizer, à possessão comum dos próprios seres humanos. Na comunidade de lugar, as relações vinculam-se ao solo e à terra; e, na comunidade de espírito, os elos comuns com os lugares sagrados e com as divindades honradas. As três espécies de comunidades estão estreitamente ligadas entre si no espaço e no tempo, e, em conseqüência, em cada um de seus fenômenos particulares 
e seu desenvolvimento, como na cultura humana geral e sua história (TöNNIES, 1995a, p. 239).

A sociedade - ou Gesellschaft -, diferentemente da comunidade, não é demarcada espacialmente, dentro de limites facilmente estabelecidos, podendo ter amplitude ilimitada. Grupos considerados societários (ou associativos) contam com baixo grau de integração afetiva e de coesão, possibilitando maior diferenciação e individualização de seus membros. Dessa forma, eles podem contar com conhecimentos, objetivos, práticas cotidianas e formas de agir e pensar heterogêneas, que não se integram em um todo comum. As normas se processam especificamente por meio das convenções, das leis e da opinião pública. As formas de relacionamento social são predominantemente impessoais, o que significa também menor compartilhamento de valores e baixo grau de intimidade.

Em teoria, a sociedade consiste num grupo humano que vive e habita lado a lado de modo pacífico, como na comunidade, mas, ao contrário desta, seus componentes não estão ligados organicamente, mas organicamente separados. Enquanto, na comunidade, os homens permanecem essencialmente unidos, na sociedade eles estão essencialmente separados, apesar de tudo que os une (TöNNIEs, 1995a, p. 252).

A sociedade só pode existir com um grande número de pessoas vivendo em proximidade e em um território expandido, onde possa conviver imenso número de pessoas, com os mais diversos modos de ser. Dessa forma, a sociedade se refere ao mundo moderno, às metrópoles modernas e à cultura heterogênea das cidades, onde as mais diversas variações culturais são aceitas, até com certa indiferença.

Assim, a vida comunitária se contrapõe à vida societária. Em uma, impera a homogeneidade, na outra, a heterogeneidade; em uma, encontram-se princípios gerais que orientam a ação do grupo, na outra, princípios relativos que orientam ações de membros individuais.

A comunidade só pode ter seus aspectos demarcados e delineados a partir de seu grande contraste com seu oposto moderno, a sociedade, pois, só a partir de então - do momento em que deixa de ser a única forma de relação social de grupo -, ela passa a ganhar centralidade; e, só diante da conturbada vida metropolitana - que, mesmo possibilitando um aumento dos contatos sociais, levou a uma menor profundidade desses contatos -, a coerente vida comunitária passa a ser uma metáfora de tudo o que é social. 
Nas cidades, nas capitais e, sobretudo, nas metrópoles, a vida em família entra em declínio. Quanto maior e mais extensa a influência urbana, mais os resíduos da vida familiar adquirem um caráter puramente acidental. Poucas pessoas ultrapassam pela força de vontade um círculo tão estreito. Todos são atraídos para o exterior, separados e isolados pelos negócios, interesses e prazeres (TöNNIES, 1995a, p. 346).

Similar à compreensão de Tönnies (1995a) acerca da sociedade é a visão de Georg Simmel acerca da metrópole. Para Simmel (1987), a metrópole é a expressão da individualidade, "berço" da individualidade, seguida de alta impessoalidade e de subjetividade altamente diferenciada. Na metrópole, emerge a atitude blasé, ou seja, uma incapacidade de reagir a estímulos e novas sensações. Essa atitude é resultante da intensidade e quantidade de estímulos aos quais os indivíduos são expostos cotidianamente na metrópole. Além disso, com o extensivo do grupo - como no caso dos grandes agrupamentos urbanos -, os contatos com outras pessoas se tornam menos intensos e pessoais, o que - mesmo que diminuam os laços sociais - aumenta a liberdade de ação das pessoas e dos grupos.

Tanto em Tönnies como em Weber, a ideia de comunidade aparece como uma tipologia. No caso de Tönnies, ele parte das comunidades para as associações modernas e, a partir disso, cria uma filosofia da história, e o desenvolvimento tem um rumo ao longo do tempo. Mas não se trata apenas disso. Tönnies converte o caso específico que lhe era disponível - a diferença histórica entre comunidade e sociedade - em uma classificação que busca dar conta da análise de qualquer sociedade do passado e do presente (NISBET, 1967, p. 74). Da mesma forma, tanto para Tönnies quanto para Weber, a comunidade deve ser entendida como um tipo ideal, um construto intelectual útil para a análise de grupos sociais, mas que deve considerar que, na realidade, comunidade e sociedade se misturam.

De certo modo, pode-se verificar em Tönnies uma visão pessimista da modernidade. De seu ponto de vista, aquilo que a Sociologia chamou de "social" se encontra principalmente na comunidade. É nela que se encontram a relação social mútua e os códigos morais compartilhados; é nela que o afeto predomina e determina os laços entre as pessoas. Porém, com a modernidade e a decadência da vida comunitária, o que se vê mesmo é a decadência deste "velho social". A sociedade emergente é, para ele, sinônimo de atomização e individualização radicalizada e, assim, não pode representar uma forma de reconstrução da vida comunitária e de seu aspecto afetivo, pessoal e agregador. 


\section{SOLIDARIEDADE: MECÂNICA E ORGÂNICA}

Em Durkheim (1978b) também se encontra uma formulação da ideia de comunidade. Mesmo que muitas vezes não seja explícito, em seu conceito de solidariedade mecânica, encontram-se "ressonâncias" da vida comunitária das pequenas aldeias. Também a individualização ganha seu lugar, em decorrência da diferenciação dos indivíduos nas sociedades orientadas pela solidariedade orgânica. E, mesmo que não faça referência direta a Tönnies - e mesmo que suas conclusões sobre as diferentes formas de solidariedade sejam ligeiramente diferentes das concepções de comunidade e sociedade -, de modo geral, encontra-se uma conceituação que permite entender as ideias de ambos os autores como referentes.

Encontram-se essas ideias na obra de Durkheim (1978b) sobre a divisão do trabalho social. O conceito de divisão do trabalho social se refere aos variados níveis de diversificação e especialização presentes nas sociedades. Para ele, a divisão do trabalho não tem uma função meramente econômica ou produtiva, ela também tem uma função social mais abrangente: seu objetivo é gerar solidariedade social.

Assim somos conduzidos a considerar a divisão do trabalho sob um novo aspecto. Neste caso, com efeito, os serviços econômicos que ela pode prestar são pouca coisa ao lado do efeito moral que ela produz, e sua verdadeira função é de criar entre duas ou várias pessoas um sentimento de solidariedade (DurkHEIM, 1978b, p. 27).

Essa solidariedade pode ser traduzida em termos de um código moral que rege a vida em grupo. De fato, a forma mais clara pela qual a solidariedade opera é a moral; e esta funciona como uma obrigação mútua que abarca todo um grupo social. Não se trata apenas de uma obrigação coercitiva, ela também tem seu lado "voluntário". Abrangendo todo o grupo social, em seu aspecto cotidiano, a solidariedade pode funcionar como uma dádiva mútua, sendo "indissociavelmente 'livre e obrigada' de um lado, e interessada e desinteressada do outro” (CAILLÉ, 1998, on-line).

O caminho encontrado por Durkheim (1978b) para investigar as formas de solidariedade nos diversos tipos de sociedade é o estudo do Direito. E por que o Direito? O Direito é o objeto escolhido porque nele pode ser vislumbrada a objetivação dos códigos morais sociais em normas, regras e leis. O Direito é a racionalização da moral, e, a partir dessa racionalização, Durkheim (1978b, p. 24) pode encontrar duas formas de encarar o fenômeno da solidariedade social: uma 
é exprimida pelo Direito Penal ou coercitivo, e a outra é exprimida pelo Direito Restitutivo. Nas palavras do autor:

Existem dois tipos. Umas consistem essencialmente numa dor, ou, pelo menos, numa diminuição infligida ao agente; têm por objeto atingi-lo em sua fortuna, ou em sua honra, ou em sua vida, ou em sua liberdade, privá-lo de algo que desfruta. Diz-se que são repressivas; é o caso do direito penal. [...] Quanto ao outro tipo, ela não implica necessariamente um sofrimento do agente, mas consiste somente na restituição das coisas nas devidas condições, no restabelecimento das relações perturbadas sob sua forma normal, quer o ato incriminado seja reconduzido à força ao tipo do qual foi desviado, quer seja anulado, isto é, privado de todo valor social. Portanto, devemos dividir as regras jurídicas em duas grandes espécies, segundo tenham sanções repressivas organizadas ou sanções apenas restitutivas.

É importante para a investigação das formas de solidariedade a ideia de consciência coletiva. Trata-se de um conceito fundamental, de um fenômeno que constitui a base de toda e qualquer vida comunitária e mesmo de qualquer existência social que permaneça ao longo dos tempos. A consciência coletiva atua não só como uma norma, mas também como todo um imaginário que orienta a vida social.

O conjunto de crenças e dos sentimentos comuns à média dos membros de uma mesma sociedade forma um sistema determinado que tem sua vida própria; poderemos chamá-lo: consciência coletiva ou comum. Sem dúvida, ela não tem por substrato um órgão único; é, por definição, difusa em toda a extensão da sociedade; mas não deixa de ter caracteres específicos que fazem dela uma realidade distinta. Com efeito, é independente das condições particulares em que os indivíduos estão colocados; eles passam, ela permanece. [...] não muda a cada geração, mas, ao contrário, liga uma às outras gerações sucessivas. Portanto, é completamente diversa das consciências particulares, se bem que se realize somente entre indivíduos. Ela é o típico psíquico da sociedade (DurkHEIM, 1978b, p. 40).

A conceituação a seguir - fundamentada na divisão do trabalho e expressa nas formas de Direito - oferece a solidariedade mecânica e a solidariedade orgânica, conceitos que visam ao entendimento dos aspectos qualitativamente diferentes da vida social. 
A solidariedade mecânica é aquela expressa pelo Direito coercitivo, no qual as ofensas contra a moral do grupo são meramente punidas - servindo de exemplo aos outros membros do grupo. Em uma sociedade integrada por essa forma de solidariedade, as formas de pensar e agir e a moral que as orienta encontram grande abrangência entre os membros da sociedade, integrando cada um deles. A diferenciação entre os membros do grupo é baixa, e há um vínculo moral que os une.

A primeira [a solidariedade mecânica] só pode ser forte a medida em que as idéias e as tendências comuns a todos os membros da sociedade ultrapassam em número e em intensidade as que pertencem pessoalmente a cada um deles. [...] Ora, o que faz nossa personalidade é o que cada um de nós tem de próprio e de característico, é o que o distingue dos outros. Portanto, esta solidariedade apenas pode crescer na razão inversa da personalidade. [...] A solidariedade que deriva das semelhanças está em seu maximum quando a consciência coletiva recobre exatamente nossa consciência total e coincide em todos os pontos com ela: mas, neste momento, nossa individualidade é nula. Ela só pode nascer se a comunidade ocupa menos lugar em nós (DurkHEIM, 1978b, p. 69).

Diferentemente, a solidariedade orgânica é aquela expressa pelo Direito restitutivo, pelo qual as ofensas contra a moral do grupo devem servir para reparar o dano que foi conferido à sociedade, e não como uma mera punição “exemplar". Em uma sociedade integrada por essa forma de solidariedade, as formas de pensar e agir são diversas, e existe uma mais ampla liberdade na definição das orientações morais - sendo estas cada vez menos equivalentes à consciência coletiva e podendo ser definidas por disposições individuais. Aqui, a diferenciação entre os membros do grupo é elevada, e os códigos morais não encontram grande abrangência totalizante, não vindo a integrar cada um dos membros da sociedade.

É completamente diferente a solidariedade produzida pela divisão do trabalho. Enquanto a precedente implica que os indivíduos se assemelhem, esta supõe que difiram uns dos outros. A primeira só é possível na medida em que a personalidade individual é absorvida pela personalidade coletiva. A segunda é apenas possível se cada um tem uma esfera de ação que lhe é própria, por conseguinte, uma personalidade. É preciso, pois, que a consciência coletiva deixe descoberta uma parte da consciência individual, para que aí se estabeleçam estas funções especiais que ela não pode regulamentar; quanto mais extensa esta região, tanto mais forte é a coesão resultante desta solidariedade. Por outro lado, cada um 
depende tanto mais estreitamente da sociedade quanto mais dividido é o trabalho, e, além disto, a atividade de cada um é tanto mais pessoal quanto mais especializada (DurкheIм, 1978b, p. 70).

A preocupação de Durkheim é a radicalização da divisão do trabalho a partir do século XIX e suas consequências gerais sobre as sociedades. Maior divisão do trabalho significa maior especialização. Se, por um lado, isso gera maior individualização dos indivíduos, por meio de sua diferenciação em relação à maioria, por outro, gera maior integração, por meio da interdependência entre pessoas que dispõem de habilidades das quais outros indivíduos necessitam. Individualização e integração atuam em conjunto nessa visão sobre a modernidade, e a diferenciação não implica apenas dissociação, como parece pensar Tönnies.

No entanto, e para isso Durkheim se encontrava alerta, existia o risco da anomia, a qual se refere à falta de integração, de normas que regulamentam a vida social. Tanto a sociedade pode ser anômica, na medida em que não ofereça normas que orientem os indivíduos em suas ações, como também os indivíduos podem ser anômicos, na medida em que não se sintam integrados, de alguma forma, à sociedade da qual fazem parte. A anomia parece ser fruto de uma rápida mudança social ocorrida desde a Revolução Industrial e também a Revolução Francesa e parece relacionada à crise dos valores tradicionais e à incapacidade de integração social no mundo moderno. Porém, para ele, o estado normal da sociedade contemporânea é o de solidariedade orgânica, ou seja, uma nova forma de integração. Dessa maneira, a anomia não é algo permanente, e, como um organismo, a sociedade tende a se reorganizar e eliminar o que lhe é prejudicial. Logo, a sociedade moderna, ao menos em graus de integração, em estados normais, não difere muito de uma comunidade aldeã.

Em Durkheim (1978a), a comunidade não aparece apenas como uma forma de organização social, mas também como uma metodologia que visa dar conta do entendimento de fatos relacionados à moralidade, ao Direito, à religião, etc. Isso pode ser mais bem evidenciado em suas Regras do método sociológico, obra em que as características comunitárias, expostas na ideia de solidariedade mecânica, são consideradas atributos dos fatos sociais. Dessa forma, a Sociologia deveria ocupar-se da tradição e de fatos coercitivos e externos ao indivíduo (NisBet, 1967, p. 86). É nas normas e na moralidade que podem ser encontradas as maiores expressões de tudo o que é social, e é justamente no fenômeno da vida comunitária - que para ele é o "espírito" da sociedade - que a moral deve ser investigada. 
A Sociologia deve investigar a moralidade, que é sempre coletiva, mas, como esta apenas pode ser expressa na vida em grupo, a comunidade aparece como uma forma de apreensão do social, uma forma de ter acesso ao fenômeno da moralidade, que é o fenômeno mais estritamente social.

Simmel, mesmo que em uma abordagem bastante diferente da de Durkheim, tratou da comunidade em termos bastante similares. Em sua microssociologia, há um interesse pelos caracteres comunitários encontrados no cotidiano, principalmente nos fenômenos de amizade, lealdade, amor, dependência, gratidão, confidência, entre outros (Nisbet, 1967, p. 101). Pergunta-se: o que há de comum em todos esses fenômenos se não a obrigação recíproca que liga os que se envolvem dessa forma nas relações sociais? Essa obrigação recíproca se mostra em uma moral comum, naqueles traços da solidariedade mecânica que são constituintes dos fatos sociais.

De certa forma, Durkheim, com seus conceitos de solidariedade, buscava fazer uma crítica do sujeito hegemônico do utilitarismo. $\mathrm{O}$ individualismo utilitarista considerava o sujeito como primordial e entendia a sociedade como formada pelas ações de sujeitos que buscavam apenas seus interesses individuais. Durkheim, em sua formulação de uma teoria da sociedade que considerasse os aspectos compartilhados da ação humana - aspectos esses verificáveis na moral, nas tradições e nos costumes -, efetuava, assim, uma crítica ao utilitarismo e à suposta independência do indivíduo que evocava. Dessa forma, para além de uma crítica específica ao utilitarismo, sua crítica se dirigia também à visão de que a sociedade moderna era especialmente mais atomizada e individualista do que sociedades do passado.

[...] eu acredito que toda a vida de grandes aglomerações sociais é tão natural quanto a de pequenas agregações. Ela não é nem menos orgânica nem menos internamente ativada. Para além das ações puramente individuais, há, em nossas sociedades contemporâneas, um tipo de atividade coletiva que é tão natural quanto a das sociedades menos extensas dos dias do passado (DurkheIM, 1995, p. 118).

Poder-se-ia dizer que, em Durkheim, há uma visão otimista da modernidade, principalmente se for pensada sua perspectiva em contraposição à de Tönnies. Também para Durkheim, da mesma forma que para Tönnies, aquilo que a Sociologia chamou de "social" se encontra principalmente na comunidade. No caso, comunidade é sinônimo da solidariedade mecânica, e o fato social é aquele fato coercitivo que caracteriza essa solidariedade. Não há, para ele, porém, com a modernidade, uma decadência das formas de vida social. A modernidade, com 
sua solidariedade orgânica, ao mesmo tempo em que gera diferenciação e individualização, gera também uma nova forma de integração que se fundamenta na interdependência de indivíduos qualitativamente diferentes.

Mesmo diante do risco da dissociação do social, Durkheim não considera a modernidade como uma ordem essencialmente anômica - a anomia é apenas transitória. A sociedade caracterizada pela solidariedade orgânica é tão natural quanto aquela caracterizada pela solidariedade mecânica. Não se trata de uma sociedade que se mantém unida apenas artificialmente, mas de uma gradual mudança do meio pelo qual as sociedades se integram.

\section{COMUNIDADES ÉTICAS E ESTÉTICAS}

Bauman (2003), partindo de Tönnies e da ideia de que a comunidade necessita de um entendimento partilhado entre seus membros, busca superar os argumentos desenvolvidos pelo autor. Na sociedade moderna nascente, o entendimento não poderia mais ser partilhado, tendo sido substituído pelo consenso. No entanto, consenso não significa partilha, mas apenas negociação entre pessoas e interesses divergentes. O entendimento, diferentemente do consenso, não precisa ser procurado, está sempre disponível aos membros de uma comunidade. A transição da comunidade para a sociedade é também a transição do entendimento ao consenso.

A comunidade depende da "mesmidade" e, dessa forma, é alheia à reflexão, à crítica e à experimentação. Ela tem sempre que manter certa imutabilidade, caso almeje manter-se comunitária ao longo do tempo. Para a manutenção da "mesmidade", é necessário que se defina como distinta de outros grupos sociais, mas também que seja pequena e autossuficiente (BAUMAN, 2003, p. 17-18). Enquanto não houver canais de comunicação ampliados entre a comunidade e outros agrupamentos, é possível que sua homogeneidade se mantenha. Com a relativização das distâncias a partir de meios de transporte e de comunicação, a vida comunitária se torna cada vez mais insustentável.

A distância, outrora a mais formidável das defesas da comunidade, perdeu muito de sua significação. O golpe mortal na "naturalidade" do entendimento comunitário foi desferido, porém, pelo advento da informática: a emancipação do fluxo da informação proveniente do transporte dos corpos. A partir do momento em que a informação passa a viajar independente de seus portadores, e numa velocidade muito além da capacidade dos meios mais avançados de transporte [...] 
a fronteira entre o "dentro" e o "fora" não pode mais ser estabelecida e muito menos mantida (BAUMAN, 2003, p. 18-19).

A partir desse momento, toda a unidade precisa ser artificialmente construída; o entendimento é substituído pelo consenso; e a unidade é apenas alcançada por meio da negociação e da adesão racional. Nada garante também que um acordo dado por consenso não venha a ser desfeito. Não existe mais a possibilidade de um entendimento compartilhado e duradouro, como o que era oferecido pela comunidade.

Também a segurança garantida pela vida comunitária tem de ser reconstruída artificialmente. As "comunidades cercadas" com sistemas de segurança e vigia eletrônicos visam à segurança e à manutenção da intimidade de seus moradores, mas, de forma nenhuma, reconstroem uma experiência de entendimento. São refúgios de um mundo de "intrusos", de pessoas em relação às quais não se pode nutrir confiança, de um mundo inseguro (Bauman, 2003, p. 52). De um lado, há a tentativa de reinstauração da segurança nas "comunidades cercadas", mas, de outro, o cosmopolitismo anticomunitário dos que vivem sempre em transição. Estes são cidadãos globais, sempre em transição por não-lugares (AuGÉ, 1994), onde vivem a uniformidade alheia ao contato com qualquer forma significativa de diferença cultural.

Segundo Bauman (2003), diante da impossibilidade de encontrar uma comunidade, uma nova forma de haver entendimento e segurança, o conceito de identidade ganha importância. A identidade é a substituta contemporânea da comunidade. Ela incorpora a individualidade ao pertencimento a grupos ou filiações a estilos de vida, mas, de forma nenhuma, esse pertencimento pode ser similar ao pertencimento comunitário - é sempre um pertencimento temporário, revogável e precário e também incapaz de trazer a segurança trazida pela comunidade.

Uma vida dedicada à procura da identidade é cheia de som e de fúria. "Identidade" significa aparecer: ser diferente e, por essa diferença, singular - e assim a procura da identidade não pode deixar de dividir e separar. E no entanto a vulnerabilidade das identidades individuais e a precariedade da solitária construção da identidade levam os construtores da identidade a procurar cabides em que possam, em conjunto, pendurar seus medos e ansiedades individualmente experimentados e, depois disso, realizar os ritos de exorcismo em companhia de outros indivíduos também assustados e ansiosos (BAUMAN, 2003, p. 21). 
A impossibilidade de cumprir, de maneira substitutiva, o papel da comunidade deve-se, em parte, ao fato de a construção da identidade ser sempre um processo incompleto; ela nunca deve ser fixa ou determinada. A identidade é sempre flexível, sujeita a mudanças de acordo com os enfrentamentos do cotidiano; ela deve ser "vestida" para cada situação, enquanto for necessária. Em uma modernidade líquida, as identidades devem ser construídas à maneira de um bricoleur, como uma colagem de tudo o que é disponível, visando aos fins atualmente almejados (BAuman, 2005). Esse trabalho de construção permanente da identidade é visto pelos sujeitos envolvidos em sua construção como uma libertação, em comparação com as identidades fixas das comunidades pré-modernas.

A "comunidade", cujos usos principais são confirmar, pelo poder do número, a propriedade de escolha e emprestar parte de sua gravidade a que confere "aprovação social”, deve possuir os mesmos traços. Ela deve ser tão fácil de decompor como foi fácil de construir. Deve ser e permanecer flexível, nunca ultrapassando o nível "até nova ordem" e "enquanto for satisfatório" (BAUMAN, 2003, p. 62).

No entanto, o deslocamento da comunidade para a identidade como processo central de definição dos indivíduos não significa o fim da comunidade. A busca pela identidade favorece a emergência de um novo tipo de comunidade: as comunidades estéticas. Bauman (2003, p.56-68) sugere que as comunidades estéticas são fundamentalmente diferentes das comunidades éticas - que seriam aquelas descritas por Tönnies. As comunidades éticas são orientadas por normas, tradições e destinos partilhados; já as estéticas são flexíveis e mutáveis, não conferindo uma orientação moral duradoura, nem um destino partilhado, e permanecem sob o risco permanente de sua dissolução. As comunidades estéticas, criadas em consonância com as novas identidades, são reunidas em torno do entretenimento, de celebridades, de ídolos. Há um deslocamento da ética para a estética, no qual as autoridades não são mais os líderes morais, mas o exemplo das celebridades e a liberdade que representam.

Uma coisa que a comunidade estética definitivamente não faz é tecer entre seus membros uma rede de responsabilidades éticas e, portanto, de compromissos a longo prazo. Quaisquer que sejam os laços estabelecidos na explosiva e breve vida da comunidade estética, eles não vinculam verdadeiramente: eles são literalmente "vínculos sem conseqüências". [...] Como as atrações disponíveis nos parques temáticos, os laços das comunidades estéticas devem ser "experimenta- 
dos”, e experimentados no ato - não levados para casa e consumidos na rotina diária (BAUMAN, 2003, p. 67-68).

Bauman (2001, p. 227-230) também chama essas comunidades estéticas de comunidades-cabide - ou cloakroom communities. Essa metáfora pode ser entendida de duas formas. Primeiramente, são comunidades-cabide porque são vestidas por indivíduos, como trajes, e utilizadas em diversas situações; e, como trajes, elas são deixadas de lado quando saem da moda ou quando a situação não mais as exige. Mas também elas são o "cabide" onde os medos e as preocupações enfrentados individualmente são temporariamente pendurados, ou seja, deixados de lado, em nome de uma identidade vivida em conjunto, mas apenas por tempo determinado - enquanto duram as festas e os espetáculos que evocam uma identidade partilhada, mas que nunca são substitutos permanentes para uma comunidade reunida em torno de uma "causa comum”. Dessa forma, "é discutível se essas 'comunidades-cabide' oferecem o que se espera que ofereçam - um seguro coletivo contra incertezas individualmente enfrentadas" (BAUMAN, 2003, p. 21).

O que as comunidades estéticas definitivamente são incapazes de gerar são responsabilidades éticas e compromissos de longo prazo. Elas são apenas comunidades passageiras, cujo objetivo é muito mais a composição de uma identidade individual do que a construção de uma coletividade. Dessa forma, o deslocamento das comunidades éticas para as comunidades estéticas evidencia uma fase de maior individualização nas sociedades modernas; sugere que, nas sociedades integradas e globais, nas quais vivemos - onde não existem mais limitações locais e tradicionais que determinem de modo totalizante as ações e os pensamentos -, deparamo-nos com a impossibilidade de uma recriação do modo de vida comunitário, em seu sentido tradicional.

\section{NEOTRIBALISMO}

A tribo sempre foi considerada um dos principais exemplos de comunidade. Nela, o isolamento poderia garantir, com facilidade, um elevado grau de homogeneidade e integração entre seus membros. As tradições e os ritos conferiam aos seus membros um código de conduta, uma moral e um destino compartilhados, bem como um entendimento comum do mundo que os cercava.

A modernidade foi reconhecida por solapar as principais formas de comunidade, conduzindo da pessoalidade comunitária à impessoalidade societária. Junto com a perda de um sentido compartilhado, veio a necessidade de reconstrução 
individual dos sentidos. No entanto, há quem questione em que medida isso foi realmente um processo tão abrangente e se, atualmente, esse processo continua.

Michel Maffesoli sugere que não. Em sua visão, vive-se em um período pós-moderno, no qual ocorre um hibridismo de estilos de vida, em que as diversas características anteriormente ofuscadas na modernidade estão voltando à tona, sendo reintegradas ao social - e isso inclui diretamente o tribalismo, como vivência comunitária.

Os membros de uma tribo têm um sentimento comum para com sua região e, portanto, para com os demais membros. Este sentimento evidencia-se no orgulho com que falam de sua tribo enquanto objeto de lealdade, na depreciação jocosa de outras tribos e na indicação de variações culturais em sua própria tribo como símbolos de sua singularidade (Evans-Pritchard, 2007, p. 132).

Para Maffesoli, tudo o que caracterizava as tribos - exaustivamente estudadas pela etnologia e em estudos etnográficos - também está presente nos grupos sociais contemporâneos. As novas tribos, presentes nas grandes metrópoles, representam uma ruptura com o individualismo moderno e com a perspectiva impessoal da vida urbana: "se a distinção é, talvez, uma noção que se aplica à modernidade, por outro lado, ela é totalmente inadequada para descrever as diversas formas de agregação social que vêm à luz" (MAFFESOLI, 2006, p. 39). O que o autor sugere é uma substituição de um social racionalizado por uma socialidade empática.

As novas tribos urbanas são, para Maffesoli (2006, p. 40), similares às comunidades emocionais de Weber, que eram encontradas nas religiões, independentemente de seu grau de institucionalização e racionalização ${ }^{1}$. Suas características seriam o aspecto efêmero, a composição cambiante, a inscrição local, a ausência de uma organização formal e a estrutura cotidiana. O que predomina aqui é uma espécie de desindividualização, fato que permite compreender que essa nova forma de sociabilidade não é tão nova assim, mas justifica o uso do termo tribalização, por remeter às tribos, à Gemeinschaft. Existe, aqui, a substituição de uma perspectiva política ou progressista por uma aura estética.

1 Para Weber (1987), a comunidade é uma relação social, na medida em que a orientação da ação social fundamenta-se em um sentido de solidariedade, resultado de ligações emocionais. Ela é resultado de uma relação cujo fundamento é um sentimento de pertencimento experimentado pelos participantes e cuja motivação tem como base qualquer espécie de ligação emocional ou afetiva. Para ele, os grupos motivados, dessa forma, estão geralmente à parte dos enrijecimentos institucionais. Por isso o uso do termo comunidades emocionais. 
De qualquer maneira, sob qualquer denominação que se lhe dê (emoção, sentimento, mitologia, ideologia), a sensibilidade coletiva, ultrapassando a atomização individual, suscita as condições de possibilidade para uma espécie de aura que vai particularizar tal ou tal época: como a aura teológica na Idade Média, a aura política no século XVIII, ou a aura progressista no século XIX. É possível que se assista agora à elaboração de uma aura estética no qual se reencontrarão, em proporções diversas, os elementos que remetem à pulsão comunitária, à propensão mística ou a uma perspectiva ecológica (MAFFESOLI, 2006, p. 42).

Também é evidenciado por Maffesoli (2006, p. 226) que, junto do "retorno" do tribalismo, no mundo contemporâneo, há um renascimento dos mitos, os quais retornam sob a forma de uma história que os grupos contam sobre si e remetem a origens "fantásticas", com seus heróis e histórias originárias. Junto com os mitos, há ainda os ritos, os quais aparecem como uma forma de organizar a vida dos grupos em torno de eventos que os reúnem. De modo geral, o rito "é uma técnica eficaz que organiza, da melhor maneira possível, a religiosidade (religare) ambiente de nossas megalópoles”.

As tribos urbanas são múltiplas e variadas, cada uma com um código ético e moral. Cada tribo atribui, diversamente, sentido às suas ações e refunda uma tradição fundamentada no mito e em seus ritos. Essas tribos também orientam as identidades de seus membros. Ao se associar, o membro de uma tribo o faz com uma identidade partilhada e, dessa forma, não se trata apenas de uma identidade individual, mas de uma identidade comum à tribo a que pertence. Contudo, mesmo que partilhe uma identidade, o membro de uma tribo não partilha apenas aquela identidade ou é membro apenas daquela tribo. O novo tribalismo, ao contrário do antigo, permite a integração em diversas tribos e o hibridismo de diversas identidades de grupo, que, juntas, compõem uma identidade individual.

Participando de uma multiplicidade de tribos, as quais se situam umas em relação às outras, cada pessoa poderá viver sua pluralidade intrínseca; suas diferentes "máscaras" se ordenando de maneira mais ou menos conflitual, e ajustando-se com as outras "máscaras" que a circundam (MAFFESOLI, 2006, p. 238).

Dessa forma, as diversas pessoas "passeiam" pelos grupos, e os grupos cruzam-se todo o tempo. Em uma metrópole moderna, a situação com que se depara é de uma heterogeneidade que, para além de um isolamento de grupos em seus próprios valores e estilos de vida, permite sua interlocução por intermédio de indivíduos que integram vários grupos simultaneamente. 
A necessidade metropolitana de integrar vários ambientes diversos, com seus códigos específicos e separados no tempo e no espaço, permite a criação de uma identidade diversa, que é composta por várias tribos. Escolas, empresas, bares, restaurantes, pontos de encontro, todos os lugares frequentados contam com seus grupos tribais, e a necessidade de transitar por todos os lugares permite uma identidade híbrida, fruto de um cruzamento de tribos e estilos de vida. É nesse sentido que a metáfora da rede, ultimamente muito utilizada nas ciências sociais ${ }^{2}$, faz sentido. Entender a sociedade como rede permite enxergar esses cruzamentos de indivíduos e grupos, essas múltiplas associações.

O paradigma da rede pode, então, ser compreendido como a re-atualização do antigo mito da comunidade. Mito, no sentido de alguma coisa que, talvez, jamais tenha existido, age, com eficácia, no imaginário do momento. Daí a existência dessas pequenas tribos, efêmeras, mas que nem por isso deixam de criar um novo estado de espírito que parece destinado a durar (MAFFESOLI, 2006, p. 239).

As tribos aparecem, vistas desse modo, como uma possibilidade de integração dentro das sociedades modernas. Aqui não existe mais a Gesellschaft, mas uma solidariedade orgânica, em que indivíduos se integram em diversos níveis, de acordo com seus atributos específicos. As tribos, mesmo contando com membros passageiros e sendo elas mesmas passageiras, conferem um sentido comum e mostram-se como uma reconstrução da vida comunitária, ainda que difusamente. A vivência tribal permite o reconhecimento da individualidade, mas não leva ao atomismo. Ela opera uma integração entre tribo e indivíduo, compondo uma identidade que integra a participação em diversas tribos e que atesta não ser a vivência contemporânea puramente individualista.

\section{COMUNIDADE VERSUS IDENTIDADE}

No que foi debatido anteriormente, nas teorias que versam sobre a comunidade, sejam as clássicas, sejam as contemporâneas, encontra-se um tema recorrente: a

2 Exemplo disso é encontrado no trabalho de Castells (1999), que nos fala de uma sociedade em rede, na qual o mundo globalizado está inserido por meio das novas tecnologias da comunicação e/ou suas consequências, de modo que o local e o global venham a interagir incessantemente, e o tempo e o espaço são deslocados. Em uma sociedade em rede, grupos e indivíduos não são automaticamente referidos. Indivíduos podem integrar grupos diversos, em distâncias espaciais esparsas; e grupos, da mesma forma, podem articular-se com outros grupos, como uma rede de interações, integrações e trocas. 
comunidade sempre é entendida como algo situado no passado, e o que se mostra hoje é algo fundamentalmente diferente. Há também certo consenso em torno da ideia de que os tempos atuais geram maior diferenciação, por vezes, significando uma dissociação dos grupos, outras vezes, uma integração destes. Serão revistos, então, alguns dos aspectos que ficaram pouco claros, bem como será definido o que há de comum e o que há de diferente entre as abordagens que foram discutidas.

Primeiramente, algo que nos aparece como problemática é a metáfora do mecânico e do orgânico na teoria social clássica, em Durkheim e Tönnies ${ }^{3}$. Para Tönnies, a comunidade é orgânica, e a sociedade, mecânica, pois as relações sociais na comunidade são naturais e espontâneas, enquanto na sociedade são necessárias regras artificiais - e, por isso, mecânicas - para que uma unidade seja mantida.

Para Durkheim, o equivalente da comunidade é designado por solidariedade mecânica, e o equivalente à sociedade moderna é a solidariedade orgânica. Para ele, ambas as formas de solidariedade são naturais: a primeira é mecânica, pois cada membro faz parte de um todo, como se fosse peça de uma engrenagem; e a segunda é orgânica, pois os indivíduos são relativamente autônomos, agindo com elevados graus de espontaneidade e integrando-se no corpo da sociedade.

Para Tönnies (1995a, p. 231-232), todavia, "na comunidade, há uma ligação desde o nascimento, uma ligação entre os membros tanto no bem-estar quanto no infortúnio. Já na sociedade, entra-se como quem chega a uma terra estranha”. Este parece ser o pensamento não só de Tönnies, mas também de Durkheim. Mesmo que viessem a divergir em alguns pontos, seus diagnósticos sobre a modernidade indicavam um contexto de maior individualização, diferenciação e menor partilha de valores comuns.

Na Sociologia contemporânea, em Bauman (2001; 2003; 2005) e Maffesoli (2006), encontram-se divergências, mas também uma convergência. Para ambos, o atual contexto de vida, moderno-líquido ou pós-moderno, leva ao deslocamento de uma vivência ética para uma experiência estética. Em Bauman (2003), isso aparece como "comunidades estéticas" e, em Maffesoli (2006), no "tribalismo". A convergência entre eles se encontra no fato de ambos indicarem o crescimento de uma vivência efêmera nos tempos atuais, mesmo que Bauman acredite em dissociação social, que a vivência efêmera do momento seja apenas um paliativo em um caminho rumo à individualização radical ou atomização e que Maffesoli

3 As críticas de um autor ao outro, nas resenhas que fizeram (DuRkheim, 1995; TöNnIEs, 1995b), referem-se basicamente ao uso da metáfora do mecânico e do orgânico e também ao caráter integrador ou dissociador das sociedades modernas. 
acredite que a vivência efêmera do momento presente, em conjunto, leve a uma nova forma de integração social.

Os conceitos de comunidades estéticas e de tribalismo indicam um deslocamento da comunidade para a identidade, o que é decisivo sobre a sociabilidade contemporânea. A maior diferenciação e independência dos indivíduos de um todo social homogêneo que determine por completo suas vidas favorece esse deslocamento. Por isso, pode-se ser levado a acreditar que, em uma sociedade onde a diferenciação é maior, a identidade torna-se mais relevante e que, mesmo que a integração em torno de ideias e valores comuns esteja presente nas comunidades estéticas e nas neotribos, elas não oferecem uma orientação moral ou uma norma de conduta que caracterizam a comunidade. A identidade é a comunidade individualizada, a substituta moderna da comunidade.

De certa forma, o que se pode encontrar em Bauman e Maffesoli são leituras complementares a Tönnies e Durkheim ou, então, releituras de um mesmo problema. Bauman (2003) converge com Tönnies em suas conclusões e busca explicar a "lógica" dos grupos societários, nos quais, mesmo juntos, não conseguem romper com a individualização. Já Maffesoli (2006) converge com Durkheim e encontra no tribalismo uma solidariedade orgânica e a forma pela qual as sociedades atuais se integram, apesar das diferenças individuais entre seus membros. Todos os autores tematizam, cada um de sua forma, o choque entre comunidade e individualização, e, mesmo diante de suas diferentes conclusões, são encontrados problemas e similaridades que permanecem, desde os clássicos até os contemporâneos.

No mais, deve-se chamar a atenção para a mudança do estatuto da Sociologia clássica, quando comparada com a Sociologia contemporânea, e as consequências disso para a forma como são encaradas as comunidades. Autores como Durkheim ou Tönnies estavam muito preocupados em compreender as mudanças pelas quais passavam as sociedades em um período em que as consequências da modernidade começavam a deixar suas marcas de modo mais evidente. Sua preocupação era o modo de vida instaurado pelas sociedades industriais e a ruptura com uma sociedade orientada pelas tradições. Na Sociologia contemporânea, com maior distanciamento cronológico dessas questões, o problema passa a ser encontrar onde estariam as comunidades e se, após tantas mudanças radicais e incessantes, não pudessem ser encontradas, o que haveria em seu lugar. Almeja-se, assim, responder de que formas os grupos se formam e como oferecem - e se oferecem um sentido partilhado, mesmo diante de um processo ampliado de diferenciação e individualização. 


\section{REFERÊNCIAS BIBLIOGRÁFICAS}

AugÉ, Marc. Não-lugares: introdução a uma antropologia da supermodernidade. 1. ed. Campinas: Papirus, 1994.

Bauman, Zygmunt. Modernidade líquida. 1. ed. Rio de Janeiro: Jorge Zahar, 2001.

. Comunidade: a busca por segurança no mundo atual. 1. ed. Rio de Janeiro: Jorge Zahar, 2003.

Identidade: entrevista a Benedetto Vecchi. 1. ed. Rio de Janeiro: Jorge Zahar, 2005 .

CAIllé, Alain. Nem holismo nem individualismo metodológicos: Marcel Mauss e o paradigma da dádiva. Revista Brasileira de Ciências Sociais, São Paulo, v. 13, n. 38, p. 5-38, 1998. Disponível em: <http://www.scielo.br/scielo.php?script=sci_arttext\& pid=S0102-69091998000300001>. Acesso em: 12 set. 2011.

CAstells, Manuel. A sociedade em rede. 9. ed. São Paulo: Paz e Terra, 1999.

Durkheim, Émile. As regras do método sociológico. In: DurkheIm, Émile. Durkheim - Os pensadores. São Paulo: Abril Cultural, 1978a.

. Da divisão do trabalho social. In: Durkнeıм, Émile. Durkheim - Os pensadores. São Paulo: Abril Cultural, 1978b.

Uma resenha de Ferdinand Tönnies, Gemeinschaft und Gesellschaft: abhandlung des communismus als empirischer kulturformen. In: Miranda, Orlando de. Para ler Ferdinand Tönnies. 1. ed. São Paulo: EdUSP, 1995. p. 113-118.

Evans-Pritchard, E. E. Os Nuer: uma descrição dos modos de subsistência e das instituições políticas de um povo nilota. 2. ed. São Paulo: Perspectiva, 2007.

Houarss, Antônio et al. Dicionário eletrônico Houaiss da língua portuguesa. Versão 1.o. Rio de Janeiro: Editora Objetiva, 2001.

Maffesoli, Michel. O tempo das tribos: o declínio do individualismo nas sociedades de massa. 4. ed. Rio de Janeiro: Forense Universitária, 2006.

NisBet, Robert. The sociological tradition. 1. ed. London: Heinemann, 1967.

Simmel, Georg. A metrópole e a vida mental. In: VelHo, Otávio (Org.). O fenômeno urbano. Rio de Janeiro: Ed. Guanabara, 1987.

TönniEs, Ferdinand. Comunidade e sociedade. In: Miranda, Orlando de. Para ler Ferdinand Tönnies. 1. ed. São Paulo: EdUSP, 1995a. p. 231-352.

Ferdinand. Uma resenha de La division du travail social, de Emile Durkheim.

In: Miranda, Orlando de. Para ler Ferdinand Tönnies. 1. ed. São Paulo: EdUSP, 1995b. p. 118-120.

Weber, Max. Conceitos básicos de Sociologia. São Paulo: Editora Moraes, 1987. 